\title{
Formação de Mediadores e Temas Controversos nos Museus
}

\section{Djana Contier}

Faculdade de Educação da USP

djanacontier@gmail.com

\section{Martha Marandino}

Faculdade de Educação da USP

marmaran@usp.br

\begin{abstract}
Resumo
Com o objetivo de fomentar as discussões sobre as relações entre ciência, tecnologia e sociedade nos museus, o presente artigo discutiu as estratégias de formação dos educadores na medição de temas controversos no contexto de exposições de ciências, a partir de um curso ministrado em parceria com o Museu de Microbiologia do Instituto Butantan. A estrutura e as atividades do curso tiveram como inspiração a ferramenta metodológica de mapeamento de controvérsias (VENTURINI, 2010; 2012) que por sua vez advém da Teoria de Ator-Rede de Bruno Latour (2012). A intenção deste trabalho é refletir sobre os desafios e possibilidades de os educadores trabalharem com temas controversos na mediação com o público. A análise foi realizada a partir de dados de um questionário respondido pelos educadores após o curso e a discussão se pautou na relevância e nos desafios das instituições assumirem de forma sistemática a formação desses profissionais.
\end{abstract}

Palavras-chave: Controvérsias Científicas, Museus, Formação de educadores

\section{Training Mediators and Controversial Issues in Museums}

\begin{abstract}
In order to nurture discussions on the relationship between science technology and society in museums, this article discussed training strategies for educators in mediating controversial issues in the context of exhibition sciences, from a course taught in partnership with Microbiology Museum of the Butantan Institute. The structure and course activities had as inspiration the methodological tool of controversy mapping (Venturini, 2010; 2012) which in turn comes from Actor-Network Theory from Bruno Latour (2012). The intent of this paper is to discuss the challenges and opportunities for educators working with controversial issues in mediation with the public. The analysis was based on data from a questionnaire answered by teachers after the course and the discussion was based on the relevance and challenges of institutions systematically take their training.
\end{abstract}

Keywords: Scientific controversies, Museums, Teacher Training. 


\section{Introdução}

Cada vez mais temos encontrado pesquisas na área de comunicação e educação de ciências que investigam o papel dos museus nas discussões sobre as relações entre ciência, tecnologia e sociedade (CTS) e na promoção de uma visão crítica sobre a ciência e sua divulgação. Um aspecto focalizado nestes estudos refere-se à análise das exposições controversas nos museus de ciências, que buscam analisar as repostas, interesses, motivações do público e as formas e possibilidade de comunicação (PEDRETTI, 2004; NAVAS; PEDRETTI, 2015; YANEVA et al, 2009) e as problemáticas (limitações e desafios) que envolvem a produção destas exposições (MAZDA 2004; DELICADO, 2009). No entanto, poucas investigações possuem como foco os educadores, suas ideias, os desafios que encontram ou mesmo como se dá a participação desses profissionais na mediação dos temas controversos em exposições e outras ações educativas dos museus.

Diante deste cenário e com o objetivo de contribuir com o crescimento das discussões sobre este tema, o presente artigo irá discutir estratégias de formação dos educadores na medição de temas controversos no contexto de exposições de ciências. As ideias aqui apresentadas foram desenvolvidas a partir de um estudo que, entre outros aspectos, identificou as inquietações e questões levantadas nos processos de formação e nas práticas desenvolvidas pelos educadores ao trabalharem com temas controversos, possibilitando o mapeamento das tensões, dos desafios e das possibilidades de trabalhar com estes tópicos em espaços não formais de educação.

Vamos, ao longo deste texto, trazer elementos para responder duas questões principais: Quais conteúdos e estratégicas didáticas podem contribuir para a formação de educadores de museus para trabalhar com esses temas? Como esses conteúdos e estratégias podem contribuir para que esses profissionais se sintam melhor preparados para executar essa tarefa?

Para responder essas questões iremos analisar o curso de formação concebido para os educadores e estagiários que trabalham no Museu de Microbiologia do Instituto Butantan. A proposta deste curso de formação está inserida em uma pesquisa de doutorado que tem como objetivo compreender o papel dos educadores nas discussões sobre ciência, tecnologia e sociedade (CTS), concentrando-se nas controvérsias científicas, a partir das práticas educativas e da formação desses profissionais. A estrutura e as atividades do curso tiveram como inspiração a ferramenta metodológica de mapeamento de controvérsias apresentadas por Venturini (2010), que por sua vez advém da teoria de ator-rede de Bruno Latour, como será descrito na próxima sessão.

Desse modo, este texto busca, por um lado, apresentar o curso desenvolvido e realizar uma análise crítica sobre esta experiência buscando refletir sobre o potencial e os limites dessas estratégias de formação sobre temas controversos nos museus de ciências. 


\section{Mapeamento de controvérsias}

O mapeamento de controvérsias é um método para explorar e representar controvérsias em ciência e tecnologia criado por Bruno Latour no final da década de 1990. Tommaso Venturini, que foi seu aluno, publicou, no artigo "Diving in Magma" (VENTURINI, 2010), algumas considerações sobre a utilização desta metodologia e, em sua webpage, existe uma descrição sobre como usar esta metodologia de uma maneira didática. Encontramos, neste método, um caminho para trabalhar os temas controversos com os educadores de museus e para problematizar suas possibilidades e desafios.

De acordo com Venturini, a primeira coisa a se fazer para iniciar o mapeamento é escolher uma "boa controvérsia". Afirmando que existem estratégias para verificação se sua escolha é boa ou não. O pesquisador deve identificar se a controvérsia selecionada é "aberta" e "viva", procurando fazer um recorte factível, ou seja, delimitar bem a temática tratada no estudo, sendo importante que esse recorte seja o mais específico possível. Em seguida, deve escolher os atores-chave e começar a coletar documentos sobre o tema selecionado. A sugestão é coletar a maior quantidade possível de documentos, sempre prestando atenção nas fontes de pesquisa e analisando sua relevância. Por exemplo, se forem artigos devem ser verificadas as estatísticas de citação; se forem textos é recomendada uma análise de conteúdo; se forem sites deve-se verificar seu histórico e visibilidade. As fontes de pesquisa consideradas podem ser: literatura científica ou de outra natureza, registro de patentes, dados econômicos, legislação, livros, jornais/blogs e tantas outras que julgar pertinentes e relevantes.

Depois de escolher uma controvérsia e achar grande parte dos documentos que podem dar subsídios para o mapeamento, o pesquisador deve escolher uma maneira para representar essa controvérsia. Venturini sugere, para achar a melhor forma desta representação, que essa escolha é mais estética do que técnica, ou seja, a melhor representação é aquela que se faz entender graficamente de forma mais eficiente. A seu ver, a forma escolhida para representar a controvérsia deve ser capaz de "vencer" os jargões da ciência. O autor ainda apresenta algumas sugestões sobre as formas de representação como: mapas conceituais, gráficos, mapas geográficos, linhas do tempo, análise de textos (nuvem de tags), apresentação de slides, ferramentas de visualização de debates online, figuras e desenhos e outras.

Para Venturini (2010) a forma mais usual de representação são os mapas conceituais, que de forma bem sintética podem ser definidos como "diagramas indicando relações entre conceitos ou entre palavras que usamos para representar conceitos" (MOREIRA, 2010). Essa ferramenta vem se mostrando adequada por ser a mais antiga, conhecida e flexível na maneira de representação. A grande vantagem na sua utilização é que possibilita visualizar a posição dos atores, 
sua relativa importância, suas relações e suas composições. Além disso, existem inúmeras ferramentas online de construção de mapas conceituais, o que pode facilitar bem o trabalho de mapeamento.

Em suas considerações, Venturini (2010) afirma que Bruno Latour, em suas aulas, dizia que para fazer um mapeamento de controvérsias cientificas deve-se somente observar e levar em conta o que está sendo visto, já esta técnica não requer nenhuma teoria social e nenhum protocolo metodológico No entanto, diz Venturini, quando juntamos os dois conceitos somente e controvérsias esse processo pode ser muito mais trabalhoso do que possa parecer inicialmente. A seu ver, a expressão somente significa que os pesquisadores ou alunos que forem fazer esse mapeamento devem se desarmar de qualquer arcabouço teórico-metodológico; devem usar todas as ferramentas que estiverem ao seu alcance, mesclando-as sem restrição; devem ser guiados pela surpresa e pela curiosidade, mais do que por qualquer outra coisa; não devem tentar ser imparciais por princípio; ao contrário, devem sim levantar o maior número possíveis de pontos de vistas para tentar atingir o maior grau de objetividade; e nunca devem subestimar o ponto de vista dos atores envolvidos pois eles estão "mergulhados" na questão e os pesquisadores e alunos "estão de passagem".

Importante dizer que, em nosso trabalho, usamos a definição de controvérsia proposta no projeto internacional MACOSCOL ${ }^{1}$ : "a palavra controvérsia se refere qualquer episódio da ciência e da tecnologia que não está estabelecido ainda, concluído ou dentro de uma caixa preta. Nós usamos como um termo geral para descrever incertezas compartilhadas" (MACOSPOL, 2007, s/p).

Uma controvérsia ocorre quando personagens discordam de um ponto de vista e, neste caso, a noção de discordância deve ser considerada em sua forma mais ampla. A controvérsia começa quando os personagens não podem ignorar a existência um dos outros e termina quando conseguem criar um compromisso sólido de conviver.

Vale trazer algumas características das controvérsias apresentadas por Venturini (2010): (1) envolvem todo tipo de personagem; (2) mostram a dimensão social da ciência e da tecnologia na sua forma mais dinâmica; (3) os atores discordam de tudo, inclusive da formulação da controvérsia; (4) são debatidas cada vez sobre mais coisas e cada vez por mais personagens; (5) são conflitos que envolvem relações de poder e podem envolver força e violência.

Neste contexto é importante destacar o que são considerados personagens ou atores dentro de uma controvérsia científica, com base na perspectiva de Latour (1996, 2012). Estes podem ser

\footnotetext{
${ }^{1}$ MACOSPOL (Mapeamento de Controvérsias Científicas para Política) é uma iniciativa de investigação conjunta que reúne estudiosos em ciência, tecnologia e sociedade em toda a Europa. Seu objetivo é criar uma plataforma colaborativa para ajudar estudantes, profissionais e cidadãos mapear as controvérsias científicas e técnicas. Sediado no MidiaLab em Paris.
} 
pessoas e organização de pessoas, mas também instituições econômicas, políticas, de ciência e tecnologia, o governo, e ainda incluem elementos naturais e biológicos, produtos industriais e artísticos e artefatos científicos. De acordo com Venturini (2010) para verificar se determinado elemento é um ator da sua controvérsia ou não, deve-se fazer o exercício de tentar suprimi-lo e verificar se o argumento continua sendo válido ou não. Se ele deixar de ser válido então o ator deve voltar ao mapa, se não ele pode ser excluído.

\section{Controvérsias e museus de ciências}

Exposições sobre temáticas controversas tendem a convidar os visitantes a formular pontos de vista e posicionamentos sobre os assuntos tratados (PEDRETTI, 2004). Essas exposições podem ser controvérsias seja pela natureza dos temas apresentados - controvérsias científicas ou temas em relação aos quais não existe consenso na comunidade acadêmica (HODSON, 2013) e/ou por conta das reações que elas podem gerar nos visitantes em termos de crenças, sistemas de valores e considerações morais.

Considerando os focos principais nos estudos das controvérsias anunciados por Pinch e Leuenberger (2006), nas exposições de ciência críticas, os focos mais recorrentes de estudo/apresentação de controvérsias são relacionados à sociologia da ciência e aos estudos contemporâneos de ciência e tecnologia. São aqueles que priorizam o estudo de controvérsias científicas associadas aos processos de produção de conhecimento (dentro da comunidade acadêmica), bem como a contextos que extrapolam estas comunidades como as que geram controvérsia na mídia, por conta dos atores sociais e políticos envolvidos, além das controvérsias geradas dentro da comunidade científica. Desse modo, temas críticos e complexos tendem a ser apresentados relacionando forças políticas, sociais e culturais e convidam os visitantes a se posicionarem.

Diversos autores têm contribuído para a compreensão sobre as possibilidades e desafios de se trabalhar temas controversos em museus (DELICADO 2009; MAZDA 2004, MINTZ, 2005, NAVAS; PEDRETTI, 2015, YANEVA et al, 2009). Desse conjunto de referências, Yaneva et al (2009) foram os primeiros a aplicar a metodologia do mapeamento de controvérsias para os contextos dos museus de ciências. Os autores relatam, em seu artigo, uma experiência colaborativa entre cientistas e artistas de criarem uma exposição sobre a controvérsia dos alimentos geneticamente modificados - "Mapping Controversies: The Case of Genetically Modified Food" -, 
montada na Gallery of Research ${ }^{2}$ em Viena. A montagem da exposição foi inteiramente baseada na metodologia do mapeamento de controvérsias, como uma alternativa para apresentar a ciência inacabada ou em construção (YANEVA et al, 2009). No artigo são citadas algumas das soluções expográficas utilizadas pela equipe para representar essa controvérsia, como audiovisual de manifestações de ativistas, vitrines com produtos industrializados, nuvem de tags com expressões científicas e não científicas e uma linha do tempo com os principais marcos políticos, científicos e de legislação. Na conclusão do artigo afirma-se que a experiência foi muito inovadora do ponto de vista da concepção, mas que, no entanto, nas avaliações realizadas junto ao público foi possível perceber que este não estava muito aberto a novas formas de representação da ciência.

Apesar do aumento de pesquisas que discutem o tema das controvérsias nos museus, ainda são raras as investigações centradas nos educadores. Em nosso trabalho temos como foco o estudo destes profissionais, explorando quais são as suas ideias, assim como os desafios que encontram na mediação e na formação sobre temas controversos em exposições. As reflexões apresentadas neste trabalho foram levantadas e sistematizadas a partir do curso que desenvolvemos para educadores do Museu de Microbiologia do Instituto Butantan.

\section{O curso de formação}

O curso de formação “Temas controversos e Museus de Ciências", desenvolvido para os educadores do Museu, teve três objetivos principais: subsidiar os educadores de museus de ciências a trabalhar com temas controversos a partir de exposições; elaborar estratégicas didáticas para trabalhar temas controversos na mediação em museus de ciências; e avaliar as estratégias didáticas desenvolvidas para trabalhar temas controversos na mediação em museus de ciências.

Esta ação de formação foi estruturada em quatro encontros, organizados em parceria com a coordenação do Museu de Microbiologia. No primeiro encontro, os alunos foram apresentados à temática do curso, a partir da discussão de algumas ideias básicas sobre controvérsias sóciocientificas, e realizaram duas atividades de sensibilização: "Jornal diário: o que dizem as notícias?" e "Dialogando com controvérsias". No segundo encontro, tiveram contato com a apresentação do método de mapeamento de controvérsias e, com essa referência, foram convidados a desenvolver um mapa conceitual sobre o tema das vacinas. No terceiro encontro, com a finalidade de promover a ressignificação de seu olhar sobre a exposição de longa duração do Museu, os educadores fizeram a atividade "Que objeto é esse?", levantando questões e reflexões sobre quais temáticas

\footnotetext{
${ }^{2}$ Durante seu mandato como presidente da Austrian Academy of Sciences em Viena (1991-2003), Prof. Werner Welzig iniciou a criação da "Gallery of Research". Em 2005, a Galeria organizou o evento piloto "controvérsias de mapeamento: o caso dos alimentos geneticamente modificados"
} 
controvérsias poderiam ser trabalhadas na exposição e de que maneira. No último encontro, foi proposto o desafio de elaboração coletiva do mapa conceitual das temáticas selecionadas por eles para abordagem das controvérsias neste espaço.

Como atividade final do curso, os educadores deveriam propor uma atividade a ser desenvolvida junto ao público. Na experiência realizada, os educadores desenvolveram, em grupos, três propostas de atividades. Em conjunto com a equipe de coordenação do museu, optou-se por aplicar junto ao público a atividade “As diferentes abordagens sobre a vacina contra HPV”, pelo fato de esta apresentar mais elementos discutidos durante o curso. Após a entrega da proposta da atividade, os educadores desenvolveram o roteiro da mesma, ampliando a pesquisa de conteúdo, revendo alguns pontos que precisavam ser melhor trabalhados e detalhando as estratégias. Ao final, a atividade foi realizada na forma de um piloto com duas turmas de alunos de um curso de pedagogia que visitou o Museu e, em seguida, novos ajustes foram propostos ao roteiro para sua finalização.

\section{Analisando os limites e possibilidades do curso}

No final do último encontro do curso, os educadores participantes foram convidados a responder um questionário de avalição. O questionário tinha dois objetivos principais: o primeiro era levantar as percepções dos participantes sobre as potencialidades e desafios de se trabalhar temas controversos em exposições de ciências e o segundo era avaliar o próprio curso, sua metodologia, conteúdos e forma de apresentação. Ao todo participaram 12 educadores, que responderam ao questionário proposto. Neste item iremos apresentar algumas considerações sobre os dados obtidos.

Um primeiro aspecto a ser destacado nas respostas refere-se à metodologia utilizada no curso, já que as dinâmicas propostas agradaram os educadores.

O curso proporcionou um leque de como trabalhar temas controversos, principalmente na metodologia apresentada de como selecionar um tema, busca de documentos e como analisá-los e as formas de sistematizar os argumentos e atores envolvidos. (Participante 1)

A ideia de dar voz ao maior número de atores envolvidos possível foi uma grande chave para abordar temas controversos sem ser tendencioso. (Participante 2)

Os pontos positivos levantados incluíram tanto a importância quanto os desafios de trabalhar com os temas controversos.

Gostei bastante do curso, foi evidenciando a complexidade que é trabalhar com controvérsias e ao, mesmo tempo, que não é impossível trabalhá-las com o público. Acredito que o curso vai me ajudar bastante a ver melhor esses temas, mas ainda sinto dificuldade de trabalhá-las na mediação. (Participante 3) 
As críticas ao curso aparecem com relação à distribuição das atividades e falta de tempo para discussão de temas tão densos.

Penso que o tempo foi um fator problemático, pois tudo foi "cronometrado"; as atividades precisam de um tempo maior para elaboração e organização das ideias. (Participante 5)

A partir da análise dos registros feitos durante o curso e das respostas dadas nos questionários, podemos afirmar que apesar de os participantes compreenderem a importância e relevância de se trabalhar temáticas controvérsias nos museus, muitas vezes não se sentem seguros nem preparados para este desafio. Questões relacionadas ao posicionamento pessoal e institucional, falta de informação e argumentos para discutir com o público, receio de esbarrar em questões de cunho moral ou religiosa em relação ao visitante foram encontrados na fala dos educadores.

As dificuldades seriam: barreira da própria instituição não querer abordar esses temas; insegurança dos educadores perante a sua visão ou da instituição sobre algum tema controverso; falta de formação dos educadores. (Participante 1)

A maior dificuldade que sinto em relação à mediação, saber como se colocar para que o visitante não se sinta confrontado e/ou ofendido, ter várias fontes em relação aos assuntos para mostrar que não trata-se de uma opinião pessoal do educador ou institucional. Outro ponto relaciona-se à dificuldade de revelar-se a controvérsia, pelo simples fato de a instituição não ter isso como objetivo, o que é uma dificuldade para a mediação do educador. (Participante 9)

Quando questionados sobre o assunto que poderia ser tratado caso o curso pudesse ter tido mais um encontro, nove dos dozes educadores citaram o tema abordado "Estratégias de mediação". Essas colocações mostram a necessidade de, além de discutir aspectos teóricos e metodológicos relacionados à controvérsia e ciência, o curso poderia contemplar atividades que discutissem aspectos da prática pedagógica museal.

No formato deste curso, eu sugeriria mais leitura sobre museus que apresentam controvérsias e as estratégias usadas.. (Participante 4)

Penso que seria interessante algo relacionado a prática. Como interagir com o visitante perante um tema controverso. (Participante 7)

Como indicado, atividade final do curso envolvia o desenvolvimento de uma proposta de mediação pelos educadores para trabalhar temáticas controversas. A proposta era que, além das questões conceituais trabalhadas no curso, os aspectos relativos às especificidades da educação em museus, como as estratégias de mediação, o tempo, o espaço e a exposição e seus objetos (MARANDINO, 2008) fossem considerados. No entanto, verificou-se pelas respostas dos educadores a necessidade de que esses aspectos fossem mais explorados na formação.

Ao analisar a natureza das propostas desenvolvidas pelos educadores para a mediação, percebemos que as atividades foram pautadas no que chamamos "jogo de papéis". Esta escolha sugere uma estreita relação com as etapas do mapeamento de controvérsias pois envolve a escolha 
de uma controvérsia, a identificação dos atores-chave, o levantamento de documentos e a atenção na melhor forma de representação (VENTURNI, 2010). Nesta metodologia, há uma grande ênfase no levantamento dos argumentos dos diferentes atores envolvidos nas controvérsias. Desse modo, percebeu-se que a teoria utilizada interferiu diretamente na aprendizagem dos educadores se expressando na atividade de mediação.

As respostas dos educadores, a observação do envolvimento nas atividades, as discussões geradas durante as aulas e a natureza dos trabalhos entregues, nos levam a afirmar que a utilização desta metodologia se mostrou um caminho frutífero para se trabalhar a formação de educadores de museus em temáticas controvérsias e sócio-cientificas. Contudo, o desenvolvimento das estratégias pelos educadores e a experiência de mediação desses temas junto ao público são aspectos que merecem uma atenção especial da coordenação do Museu caso a intenção seja realmente incorporar essa proposta em suas ações. Trabalhar com controvérsias junto ao público envolve desafios que não podem ser equacionados somente em um curso, devendo ser um tema explorado na formação continuada desses profissionais.

\section{Considerações finais}

Um dos grandes desafios destacados pelos educadores no trabalho com temas controversos na mediação com o público está relacionado em como equacionar as possíveis diferenças entre a opinião pessoal deles, o posicionamento institucional e a posição do visitante. Nessa perspectiva, entendemos que a ferramenta de mapeamento de controvérsias utilizada tem o potencial de ajudar os educadores a saírem dessa perspectiva auto-centrada e polarizada do "contra ou favor" de algum tema polêmico e perceberem a complexidade envolvida em temáticas controvérsias. Consideramos assim que o exercício de identificação dos diversos atores envolvidos na controvérsia é fundamental para montagem dos mapas conceituais, sendo uma etapa importante deste processo.

Trabalhar com temas controversos envolve dimensões cognitivas e afetivas, o que implica na reflexão dos educadores para lidar com as dúvidas, anseios, opiniões e posições contrárias, na perspectiva de fomentar o debate, mas também de acolher e mediar conflitos e relações. Esse é sem dúvida um dos desafios para o desenvolvimento desta temática nos espaços museais e está diretamente ligado com a formação dos educadores nesses locais.

Para Mora (2007), o sucesso das ações junto ao público envolve a formação dos mediadores, que deve ser realizada pelo próprio museu, de maneira que estes se sintam parte dele e possam imprimir uma personalidade própria à sua função. Contudo, a autora destaca que, desafortunadamente, poucos museus contam com profissionais especializados e sua função é desempenhada, ocasionalmente, por outros tipos de profissionais, muitas vezes na forma de 
colaborações voluntárias. Rodari e Mergazora (2007) apresentam um panorama geral do status e papel exercido por mediadores de museus europeus e afirmam que estes profissionais são de fundamental importância já que realizam o contato direto com o público, se constituindo em um “artifício museológico" verdadeiramente interativo, que pode dialogar, ouvir as principais questões, esperanças e preocupações a respeito do desenvolvimento científico e tecnológico e responder às reações dos visitantes, adaptando suas respostas e apresentações (RODARI; MERGAZORA, 2007).

Mora (2007) afirma ser importante que o museu, ao realizar a formação do monitor, explicite o perfil dos visitantes e suas características psicológicas e sociais e, para isso, é importante que a instituição realize levantamentos sobre seus públicos e trabalhe com esses dados junto aos educadores. As metodologias de formação dos educadores devem ainda exercitar formas de mediação que promovam a participação do público, dando liberdade para que suas ideias, percepções e opiniões apareçam. Isso envolverá, necessariamente, a habilidade do educador em lidar com as diferentes opiniões, com os conflitos e com o fato de ele nem sempre possuir as respostas para as questões e anseios do público. Este tipo de mediação necessita de um processo de formação contínuo e de uma reflexão constante sobre a prática educativa. A pesquisa aqui apresentada vai na mesma direção, na medida em que se evidenciou, inclusive na avaliação dos educadores participantes, a necessidade de que estes aspectos fossem contemplados com maior ênfase nas próximas versões do curso.

Levando em conta os aspectos mencionados, esperamos que as reflexões aqui apresentadas possam contribuir para que experiências de formação de educadores de museus com foco em temáticas controversas possam ser fomentadas e, em especial, que este tema esteja cada vez mais presente tanto nas ações de mediação como nas exposições e demais atividades educativas dos museus de ciências.

\section{Referências}

DELICADO, A. Scientific controversies in museums: notes from a semi-peripheral country. Public Understanding of Science, v.18, n. 6, p. 759-767. 2009.

HODSON, D. Don't be nervous, don't be flustered, don't be scared. Be prepared. Canadian Journal of Science, Mathematics and Technology Education, v. 13, n.4, p. 313-331. 2013.

LATOUR, B. Reagragando o social: uma introdução à teoria do Ator-Rede. EDUDBA, EDUSC, Salvador-Bauru. 2012.

MAZDA, X. Dangerous ground? Public engagement with scientific controversy. In: Chittenden, S.; FARMELO, G.; LEWENSTEIN, B. (Org.). Creating connections: museums and the public understanding of research. Walnut Creek: Altamira Press, 2004. pp. 127-4.

MINTZ, A. Science, society and science centres. História, Ciências, Saúde-Manguinhos, Rio de Janeiro, Fundação Oswaldo Cruz, Casa de Oswaldo Cruz, v. 12 (suplemento), p. 267-280, 2005. PATTON, M. Q. Qualitative Research and Evaluation Methods. $3^{\mathrm{a}} \mathrm{ed}$. SAGE, 2002 598p. 
MORA, M. DEL C. S. Diversos enfoques sobre as visitas guiadas nos museus de ciência. In Diálogos \& ciência: mediação em museus e centros de Ciência. Orgs. Luisa Massarani, Matteo Merzagora, Paola Rodari. Rio de Janeiro: Museu da Vida/ Casa de Oswaldo Cruz/Fiocruz, 2007.

MOREIRA, M. A. Mapas conceituais e aprendizagem significativa. São Paulo: Centauro, 2010.

NAVAS, A. M.; PEDRETTI. E. Exposições de ciências controversas e engajamento do público: o caso do Brasil e Canadá. In: Congreso RedPop, 14. 2015. Medellin: Libro de Memorias, 2015. p. $180-7$.

PEDRETTI, E. Perspectives on learning through research on critical issues-based science center exhibitions. Science Education, v. 88, n. 1, p. S34-S47. 2004.

PINCH, T; LEUENBERGER, C. Studying controversies from the STS perspective. In:

Proceedings of EASTS Conference "Science Controversy and Democracy". Taiwan: National Taiwan University. 2006.

RODARI, P. MERZAGORA, M. Mediadores em museus e centros de ciência: Status, papéis e treinamento. Uma visão geral européia. In Diálogos \& ciência: mediação em museus e centros de Ciência. Orgs. Luisa Massarani, Matteo Merzagora, Paola Rodari. Rio de Janeiro: Museu da Vida/ Casa de Oswaldo Cruz/Fiocruz, 2007.

VENTURINI, T. Building on faults: how to represent controversies with digital methods. Public Understanding of Science, v. 21, n. 7, p. 796-12. 2012.

VENTURINI, T. Diving in Magma: How to Explore Controversies with Actor-Network Theory. Public Understanding of Science, v.19, n.3, p.258-273. 2010.

YANEVA, A; RABESANDRATANA, T.M; GREINER, B. Staging scientific controversies: a gallery test on science museums' interactivity. Public Understanding of Science, v.18, n.1, p. 179190. 2009.

Submetido em agosto de 2016 Aprovado em outubro de 2016 